\title{
Correction to: iCanADAPT early protocol: randomised controlled trial (RCT) of clinician supervised transdiagnostic internet-delivered cognitive behaviour therapy (iCBT) for depression and/or anxiety in early stage cancer survivors -vs- treatment as usual
}

\author{
M. J. Murphy ${ }^{1 *}$, J. M. Newby ${ }^{1,2}$, P. Butow ${ }^{4}$, L. Kirsten ${ }^{3,4}$, K. Allison ${ }^{4}$, S. Loughnan ${ }^{1}$, M. A. Price ${ }^{4}$, J. Shaw ${ }^{4}$, \\ H. Shepherd ${ }^{4}$, J. Smith ${ }^{1}$ and G. Andrews ${ }^{1}$
}

\section{Correction}

After publication of the original article [1], the authors noted that the affiliation for Ms. Jessica Smith was incorrect.

In the original version of the manuscript, the affiliation is listed as affiliation 4 from the Author details list:

Psycho-oncology Co-operative Research Group (PoCoG), School of Psychology, Level 6, Chris O’Brien Lifehouse (C39Z), The University of Sydney, Sydney, NSW 2006, Australia.

However this is incorrect and the correct affiliation should be affiliation 1 from the Author details list:

Clinical Research Unit for Anxiety and Depression (CRUfAD), UNSW School of Psychiatry at St Vincent's Hospital, Level 4, O’Brien Centre, St Vincent's Hospital, 394 Victoria Street, Sydney, NSW 2010, Australia.

This has been updated in the affiliations used for this Correction.
Co-operative Research Group (PoCoG), School of Psychology, Level 6, Chris O'Brien Lifehouse (C39Z), The University of Sydney, Sydney, NSW 2006, Australia.

Received: 25 September 2017 Accepted: 25 September 2017 Published online: 02 October 2017

\section{Reference}

. Murphy MJ, Newby JM, Butow P, Kirsten L, Allison K, Loughnan S, Price MA, Shaw J, Shepherd H, Smith J, Andrews G. iCanADAPT Early protocol: randomised controlled trial (RCT) of clinician supervised transdiagnostic internet-delivered cognitive behaviour therapy (iCBT) for depression and/or anxiety in early stage cancer survivors -vs- treatment as usual. BMC Cancer. 2017;17:193. doi:10.1186/s12885-017-3182-z.

* Correspondence: michael.murphy@unsw.edu.au

${ }^{1}$ Clinical Research Unit for Anxiety and Depression (CRUfAD), UNSW School of Psychiatry at St Vincent's Hospital, Level 4, O'Brien Centre, St Vincent's Hospital, 394 Victoria Street, Sydney, NSW 2010, Australia

${ }^{1}$ Clinical Research Unit for Anxiety and Depression (CRUfAD), UNSW School of Psychiatry at St Vincent's Hospital, Level 4, O'Brien Centre, St Vincent's Hospital, 394 Victoria Street, Sydney, NSW 2010, Australia. ${ }^{2}$ School of Psychology, Faculty of Science, UNSW Australia, Mathews Building, Kensington, NSW 2052, Australia. ${ }^{3}$ Nepean Cancer Care Centre, Sydney West Cancer Network, Kingswood, NSW 2747, Australia. ${ }^{4}$ Psycho-oncology (c) The Author(s). 2017 Open Access This article is distributed under the terms of the Creative Commons Attribution 4.0 International License (http://creativecommons.org/licenses/by/4.0/), which permits unrestricted use, distribution, and reproduction in any medium, provided you give appropriate credit to the original author(s) and the source, provide a link to the Creative Commons license, and indicate if changes were made. The Creative Commons Public Domain Dedication waiver (http://creativecommons.org/publicdomain/zero/1.0/) applies to the data made available in this article, unless otherwise stated. 